\title{
Synthesis, Spectral Characterization and Biological Evaluation of Chromium(III) Complexes of Schiff Base
}

\author{
Sulekh Chandra ${ }^{*}$, Poonam Pipil ${ }^{2}$ \\ ${ }^{1}$ Department of Chemistry, Zakir Husain Delhi College, University of Delhi, Delhi, India \\ ${ }^{2}$ Department of Chemistry, Rajdhani College, University of Delhi, Delhi, India \\ Email: 'Schandra 00@yahoo.com, poonampipil@gmail.com
}

Received 15 November 2013; revised 15 February 2014; accepted 7 March 2014

Copyright @ 2014 by authors and Scientific Research Publishing Inc.

This work is licensed under the Creative Commons Attribution International License (CC BY). http://creativecommons.org/licenses/by/4.0/

(c) (i) Open Access

\begin{abstract}
Complexes of chromium(III) metal ion with schiff base i.e. 2,3,9,10 tetraphenyl-1,4,8,11-tetraazacyclotetradeca-1,3,8,10 tetraene. (BPD) 2,4,10,12-tetramethyl-1,5,9,13-tetraazacyclohexadeca1,4,9,12 tetraene. (ADP) 2,3,9,10 tetramethyl 1,4,8,11 tatraazatetredeca-1,3,8,10 tetraene (DDP) have been synthesized and characterized by elemental analysis, molar conductance, magnetic susceptibility measurements, electronic and epr spectral studies. On the basis of elemental analysis the complexes were found to have composition $\mathrm{CrLX}_{3}\left(\mathrm{X}=\mathrm{Cl}^{-}, \mathrm{NO}_{3}^{-}, \mathrm{NCS}^{-}\right)$, Molar conductance, measured in DMF solution of these complexes indicates that the complexes are 1:1 electrolytes in nature, therefore the complexes may be formulated as $\left[\mathrm{CrLX}_{2}\right] \mathrm{X}$. These complexes show magnetic moment in the range of 3.80 - 3.84 B.M. corresponding to three unpaired electrons. EPR and electronic spectral studies reveal that the complexes possess six-coordinated octahedral geometry. The ligand field parameters were calculated using various energy level diagrams. In vitro synthesized compounds and metal salts have also been tested against some species of plant pathogenic fungi and bacteria in order to assess their antimicrobial properties.
\end{abstract}

\section{Keywords}

Mass, IR, Magnetic Moment, Electronic, EPR \& Biological Activity

\section{Introduction}

Azo Schiff base complexes contain both azo and azomethine groups. The azo group possesses excellent donor

"Corresponding author.

How to cite this paper: Chandra, S. and Pipil, P. (2014) Synthesis, Spectral Characterization and Biological Evaluation of Chromium(III) Complexes of Schiff Base. Open Journal of Inorganic Chemistry, 4, 30-40.

http://dx.doi.org/10.4236/ojic.2014.42005 
properties and is important in coordination chemistry [1]-[3] and some azo compounds have shown to possess good antibacterial activity [4] [5]. Schiff bases are well known to have antifungal, antitumor and herbicidal activities [6]-[14]. Many metal complexes of naturally occurring porphyrins, corrins and phthalocyanines have been investigated because of their potential as dyestuffs or pigments. A Schiff base complex is of great importance [15]-[18] in enehancing various industrial applications and in a number of biological processes such as photosynthesis and dioxygen transport [19]. A number of reviews are available on the physiology and biochemistry of chromium in mammals [20]-[24]. In view of above applications it is highly desirable to synthesize and characterize the $\mathrm{Cr}(\mathrm{III})$ complexes with Schiff base. In view of the above in the present paper we report the synthesis and characterization of Schiff base complexes of chromium (III) with 2,3,9,10 tetraphenyl-1,4,8,11-tetraazacyclotetradeca-1,3,8,10 tetraene. (BPD) 2,4,10,12-tetramethyl-1,5,9,13-tetraazacyclohexadeca-1,4,9,12 tetraene. (ADP) 2,3,9,10 tetramethyl 1,4,8,11 tatraazatetredeea-1,3,8,10 tetraene (DDP) (Figures 1(a)-(c)).

\section{Chemistry}

All the chemicals used in the present work of high purity, Anala R grade and purchased from Sigma-Aldrich. Metal salts were purchased from E. Merck and used as received. The solvent used were either spectroscopic pure from SRL/BDH or purified by the recommended methods.

\subsection{Preparation of Ligands}

\subsubsection{Preparation of 2,3,9,10 Tetraphenyl-1,4,8,11-Tetraazacdyclo Tetradeca-1,3,8,10 Tetraene. (BPD)}

The ligand 2,3,9,10 tetraphenyl-1,4,8,11-tetraazacdyclo tetradeca-1,3,8,10 tetraene. (BPD) was synthesized by refluxing an ethanolic solution of 1,3 diaminopropane ( 0.5 mole) with an ethanolic solution of benzyl, ( 0.5 mole) in presence of $\sim 3 \mathrm{~mL}$ of conc. $\mathrm{HCl}$ for 3 - 4 hours. The resulting mixture was kept overnight, when an off-white coloured crystalline compound separated. This was then filtered, washed with ethanol, and dried over $\mathrm{P}_{4} \mathrm{O}_{10}$. The ligand is soluble in water and melted at $218^{\circ} \mathrm{C}$.

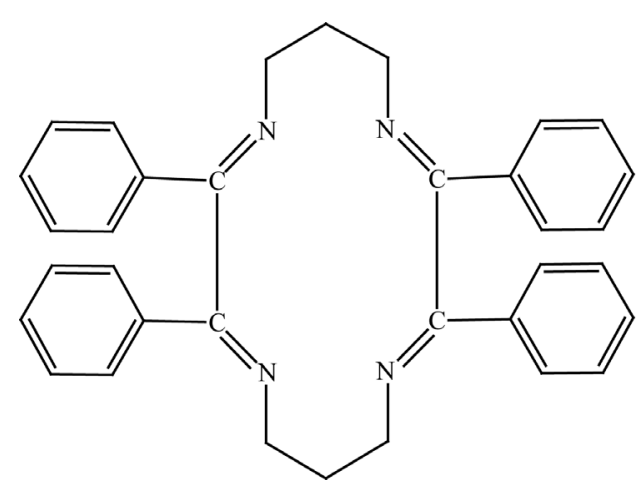

(a)

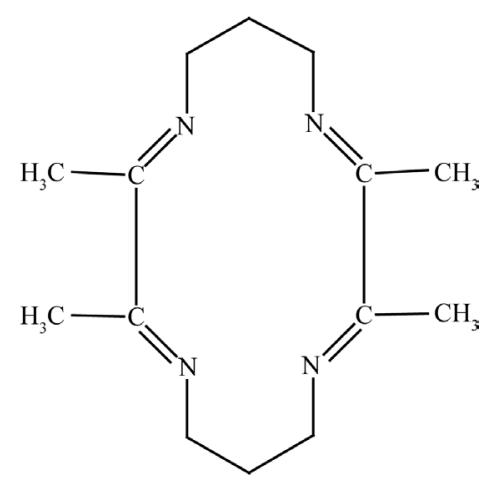

(b)

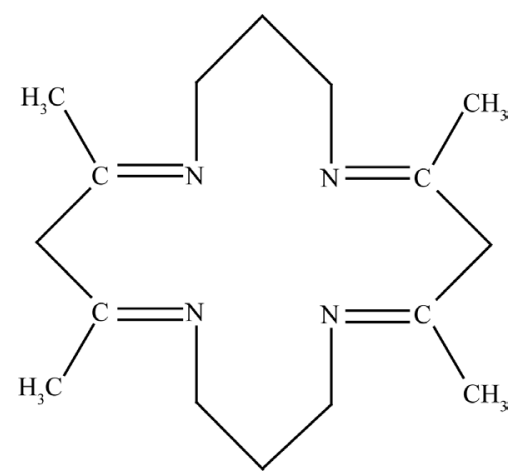

(c)

Figure 1. Structure of ligands. (a) BDP; (b) ADP; (c) DDP. 
2.1.2. Preparation of 2,4,10,12-Tetramethyl-1,5,9,13-Tetraazacyclohexadeca-1,4,9,12 Tetraene. (ADP)

2,4,10,12-tetramethyl-1,5,9,13-tetraazacyclohexadeca-1,4,9,12 tetraene. (ADP) was prepared by adding an ethanolic solution of acetylacctone ( 0.5 mole) to an ethanolic solution of 1,3 diaminopropane ( 0.5 mole) in presence of $\sim 3 \mathrm{~mL}$ conc. $\mathrm{HCl}$ and the resulting solution was refluxed for 4 hours and then kept overnight. A white crystalline compound separated on filtration which was washed with ethanol and then dried over $\mathrm{P}_{4} \mathrm{O}_{10}$. The compound was soluble in most organic solvents, and it’s melting point was recorded as $226^{\circ} \mathrm{C}$.

\subsubsection{Preparation of 2,3,9,10 Tetramethyl $1,4,8,11$ Tatraazatetredeea-1,3,8,10 Tetraene (DDP)} 2,3,9,10 tetramethyl 1,4,8,11 tatraazatetredeea-1,3,8,10 tetraene (DDP) ligand was synthesized by diactyl (0.5 mole) to an ethanolic solution of 1,3 diaminopropane ( 0.5 mole) in presence of $\sim 3 \mathrm{~mL}$ conc. $\mathrm{HCl}$ and the resulting solution was refluxed for 4 hours and then kept overnight. Light-yellow crystals separated on filtration, which were washed with ethanol and then dried over $\mathrm{P}_{4} \mathrm{O}_{10}$. The ligand is water soluble and melts at $221^{\circ} \mathrm{C}$.

\subsection{Preparation of Cr(III) Complexes with Ligands}

The complexes with these ligands were synthesized by template method because the yield of the complexes was low when the ligands were treated with metal salt to form complexes.

A hot ethanolic solution of benzil/acetylacetone/diacetyl/ ( 0.01 mole) was added to an ethanolic solution of 1,3 diaminopropane ( 0.01 mole) and the resulting solution was refluxed for half an hour at $\sim 40^{\circ} \mathrm{C}$. A solution of $\mathrm{CrX}_{3} \cdot \mathrm{nH}_{2} \mathrm{O}\left(0.005\right.$ mole) $\left(\mathrm{X}=\mathrm{Cl}^{-}, \mathrm{NO}_{3}^{-}, \mathrm{NCS}^{-}\right)$in ethanol and $\left(\mathrm{X}=1 / 2 \mathrm{SO}_{4}^{2-}\right)$ in water was then added to the above solution and refluxing was continued for a further four to six hours. On cooling the solution, a crystalline compound separated out. It was filtered, washed with ethanol and dried under vacuum over $\mathrm{P}_{4} \mathrm{O}_{10}$.

\subsection{Physical Measurement}

The C, $\mathrm{H}$ and $\mathrm{N}$ were analysed in Carlo-Erba 1106 elemental analyzer. Molar conductance was measured on a ELICO (CM82T) conductivity bridge. Magnetic susceptibility was measured at room temperature, on CAHN2000 magnetic susceptibility balance using $\mathrm{CuSO}_{4} \cdot 5 \mathrm{H}_{2} \mathrm{O}$ as a calibrant. Infrared spectra of ligands and complexes were recorded as $\mathrm{KBr}$ pellets on a Perkin-Elmer 1310 spectrophotometer. The electronic spectra of complexes were recorded in DMSO, on a Shimadzu UV mini-1240 spectrophotometer. EPR spectra of complexes were recorded on JEOL, JES, FE3XG, EPR spectrometer. The spectra were recorded in solid as polycrystalline sample at room temperature on $\mathrm{E}_{4}$-EPR spectrometer using the $\mathrm{DPPH}$ as the g-marker.

\section{Results and Discussion}

On the basis of elemental analyses (Table 1) the complexes were found to have $\operatorname{CrLX}{ }_{3}\left(\mathrm{X}=\mathrm{Cl}^{-}, \mathrm{NO}_{3}^{-}, \mathrm{NCS}^{-}\right.$) composition. Molar conductance, measured in DMF solution (Table 1) of these complexes indicates that these complexes are 1:1 electrolytes in nature, therefore, these complexes may be formulated as [CrLX $\mathrm{CrX}_{2}$.

\subsection{IR Spectra of Ligands}

The IR spectra of the ligands show vibrations corresponding to azomethine groups. The bands at 1595, 1570, 1460 and $1405 \mathrm{~cm}^{-1}$ regions can be assigned to $\mathrm{v}(\mathrm{C}=\mathrm{C})$ and $\mathrm{v}(\mathrm{C}=\mathrm{N})$ skeletal frequencies while bands appearing at 960,800 , and $407 \mathrm{~cm}^{-1}$ may be assigned to ring breathing mode, C-11 deformation and C-C deformations respectively. The strong frequencies of ca. $1595 \mathrm{~cm}^{-1}$ are usually associated to $\mathrm{v}(\mathrm{C}=\mathrm{N})$ coupled with phenyl ring vibrations. The band appearing at $1635 \mathrm{~cm}^{-1}$ may be assigned to symmetric and asymmetric $\mathrm{v}(\mathrm{C}=\mathrm{N})$ vibrations respectively. The absence of bands in the range $3300-3200 \mathrm{~cm}^{-1}$ indicates that the amino group of 2,6 diaminopyridine and 1,3 diaminopropane have condensed with the diketone molecules. The presence of bands of ca. 1680 - 1670, ca. 1550 , са. 2920, са. 1350, ca. 1265, ca. 1190 and ca. $680 \mathrm{~cm}^{-1}$ can be assigned to v(C=O), v(CO) $+\mathrm{v}(\mathrm{C}=\mathrm{C}), \mathrm{v}\left(\mathrm{CH}_{3}\right) \delta$ sym $\left(\mathrm{CH}_{3}\right), \mathrm{v}\left(\mathrm{C}-\mathrm{CH}_{3}\right), \delta(\mathrm{CH})+\mathrm{c}\left(\mathrm{C}_{-} \mathrm{CH}_{3}\right)$ and ring deformation modes respectively which indicates the presence of the diketone moiety in the ligands.

IR Spectra of the Complexes

Vibrations of free or coordinated C=O group or NH group at ca. $1680-1700$ or ca. 1550 and ca. $670 \mathrm{~cm}^{-1}$ are 
Table 1. Elemental analyses and molar conductance data of chromium(III) complexes.

\begin{tabular}{|c|c|c|c|c|c|c|c|c|}
\hline Complex & Colour & $\begin{array}{c}\text { Molar } \\
\text { Conductance } \\
\mathrm{cm}^{-1} \text { mol }\end{array}$ & $\mathrm{C}$ & $\begin{array}{c}\text { Element } \\
\text { Analysis, \% } \\
\text { Found/(calc.) H }\end{array}$ & $\mathrm{N}$ & Cr. & \% Yield & M.P.C \\
\hline$\left[\mathrm{Cr}(\mathrm{BDP}) \mathrm{CI}_{2}\right] \mathrm{CI}$ & $\begin{array}{c}\text { Bluish } \\
\text { Grey }\end{array}$ & 80 & $\begin{array}{c}62.31 \\
(62.53)\end{array}$ & $\begin{array}{c}5.25 \\
(4.90)\end{array}$ & $\begin{array}{c}8.32 \\
(8.51)\end{array}$ & $\begin{array}{c}7.45 \\
(7.90)\end{array}$ & 72 & 262 \\
\hline$\left[\mathrm{Cr}(\mathrm{BDP})\left(\mathrm{NO}_{3}\right)_{2}\right]\left(\mathrm{No}_{3}\right)$ & $\begin{array}{c}\text { Bluish } \\
\text { Grey }\end{array}$ & 87 & $\begin{array}{c}55.30 \\
(55.80)\end{array}$ & $\begin{array}{c}4.68 \\
(4.37)\end{array}$ & $\begin{array}{c}13.86 \\
(13.29)\end{array}$ & $\begin{array}{c}7.64 \\
(7.05)\end{array}$ & 69 & 273 \\
\hline$\left[\mathrm{Cr}(\mathrm{BDP})(\mathrm{NCS})_{2}\right](\mathrm{NCS})$ & $\begin{array}{l}\text { Navy Blue } \\
\text { Greenish }\end{array}$ & 92 & $\begin{array}{c}61.21 \\
(61.67)\end{array}$ & $\begin{array}{c}4.22 \\
(4.44)\end{array}$ & $\begin{array}{c}13.20 \\
(13.49)\end{array}$ & $\begin{array}{c}7.54 \\
(7.16)\end{array}$ & 63 & 276 \\
\hline$\left[\mathrm{Cr}(\mathrm{ADP}) \mathrm{CI}_{2}\right] \mathrm{CI}$ & $\begin{array}{l}\text { Blue } \\
\text { Greyish }\end{array}$ & 82 & $\begin{array}{c}44.25 \\
(44.39)\end{array}$ & $\begin{array}{c}6.22 \\
(6.47)\end{array}$ & $\begin{array}{c}12.50 \\
(12.84)\end{array}$ & $\begin{array}{c}11.50 \\
(11.91)\end{array}$ & 71 & 274 \\
\hline$\left[\mathrm{Cr}(\mathrm{ADP})\left(\mathrm{NO}_{3}\right)_{2}\right]\left(\mathrm{NO}_{3}\right)$ & $\begin{array}{l}\text { Green } \\
\text { Greyish }\end{array}$ & 95 & $\begin{array}{c}37.66 \\
(37.55)\end{array}$ & $\begin{array}{c}5.75 \\
(5.47)\end{array}$ & $\begin{array}{c}18.68 \\
(19.00)\end{array}$ & $\begin{array}{c}10.48 \\
(10.08)\end{array}$ & 69 & 280 \\
\hline$\left[\mathrm{Cr}(\mathrm{ADP})(\mathrm{NCS})_{2}\right](\mathrm{NCS})$ & $\begin{array}{c}\text { Blue } \\
\text { Greenish }\end{array}$ & 91 & $\begin{array}{c}45.36 \\
(45.60)\end{array}$ & $\begin{array}{c}5.78 \\
(5.59)\end{array}$ & $\begin{array}{c}19.66 \\
(19.43)\end{array}$ & $\begin{array}{c}10.60 \\
(10.31)\end{array}$ & 70 & 264 \\
\hline$\left.\left[\mathrm{Cr}(\mathrm{DDP}) \mathrm{CI}_{2}\right]_{\mathrm{CI}}\right] \mathrm{CI}$ & $\begin{array}{l}\text { Grey } \\
\text { Black }\end{array}$ & 88 & $\begin{array}{c}41.60 \\
(41.53)\end{array}$ & $\begin{array}{c}5.66 \\
(5.93)\end{array}$ & $\begin{array}{c}13.50 \\
(13.72)\end{array}$ & $\begin{array}{c}12.40 \\
(12.74)\end{array}$ & 64 & 268 \\
\hline$\left[\mathrm{Cr}(\mathrm{DDP})\left(\mathrm{NO}_{3}\right)_{2}\right]\left(\mathrm{NO}_{3}\right)$ & $\begin{array}{l}\text { Pinkish } \\
\text { Brown }\end{array}$ & 86 & $\begin{array}{c}34.18 \\
(34.76)\end{array}$ & $\begin{array}{c}4.32 \\
(4.96)\end{array}$ & $\begin{array}{c}20.76 \\
(20.10)\end{array}$ & $\begin{array}{c}10.84 \\
(10.66)\end{array}$ & 68 & 275 \\
\hline$\left[\mathrm{Cr}(\mathrm{DDP})(\mathrm{NCS})_{2}\right](\mathrm{NCS})$ & Dark & 90.6 & $\begin{array}{c}42.72 \\
(43.22)\end{array}$ & $\begin{array}{c}5.85 \\
(5.08)\end{array}$ & $\begin{array}{c}20.96 \\
(20.59)\end{array}$ & $\begin{array}{c}10.82 \\
(10.92)\end{array}$ & 70 & 266 \\
\hline
\end{tabular}

not observed in any of the compounds The strong bands appearing as doublets around $1590-1620 \mathrm{~cm}^{-1}$ may be assigned to $\mathrm{v}(\mathrm{C}=\mathrm{N})$ vibrations indicating the presence of coordinated azomethine groups. In these case ligands, phenyl ring absorptions appear in the $1600-1400 \mathrm{~cm}^{-1}$ region. Absorption bands in the region $900-700 \mathrm{~cm}^{-1}$ can be exclusively assigned to the imine and $-\mathrm{CH}_{2}$ absorptions of the macrocyles. IR spectral band at $\sim 450 \mathrm{~cm}^{-1}$ is characteristic of metal ligand vibrations. The lowering of the $\mathrm{v}(\mathrm{C}=\mathrm{N})$ band $\left(1620 \mathrm{~cm}^{-1}\right)$ indicates coordination through the nitrogen of $\mathrm{v}(\mathrm{C}=\mathrm{N})$ group. The bands at $1620 \mathrm{~cm}^{-1}$ and ca. $840 \mathrm{~cm}^{-1}$ may be assigned to NH deformation coupled with $\mathrm{NH}$ out of plane bending.

The appearance of new bands at $1438-1430 \mathrm{~cm}^{-1}\left(\mathrm{v}_{1}\right), 1370-1375 \mathrm{~cm}^{-1}\left(\mathrm{~V}_{3}\right), 1210-1215 \mathrm{~cm}^{-1}\left(\mathrm{v}_{5}\right), 1010$ $1015 \mathrm{~cm}^{-1}\left(\mathrm{v}_{2}\right)$ and $850-840 \mathrm{~cm}^{-1}\left(\mathrm{v}_{6}\right)$ show consistency with the monodentate nature of the nitrate group. The broad absorption band at $1405 \mathrm{~cm}^{-1}$ can be assigned to $\mathrm{v}_{3}$ of the uncoordinated nitrate group in the complex of ligand with $\mathrm{Cr}\left(\mathrm{NO}_{3}\right)_{3}$.

In thiocyanato complexes, strong bands are observed at ca. $2087\left(\mathrm{v}_{1}\right) \mathrm{v}(\mathrm{C}=\mathrm{N})$, ca. 480 $\left(\mathrm{v}_{2}\right)$ NCS banding and ca. $778 \mathrm{~cm}^{-1}\left(\mathrm{v}_{3}\right), \mathrm{v}(\mathrm{C}=\mathrm{S})$ of the NCS group, respectively which are consistent with a monodentate N-bonded thioyanato group.

\subsection{Electronic Spectra of the Complexes}

The electronic spectra of all the above complexes show bands in the region 18,000, 22,000, 25,000 and 28,000 $\mathrm{cm}^{-1}$ which are consistent with the octahedral geometry Thus, an octaheadral may be assign to these complexes. Electronic spectra of the complexes were recorded in DMF. They display four bands at 17,465 - 18,800 $\left(\mathrm{v}_{1}\right)$, 22,100 - 22,900 ( $\left.\mathrm{v}_{2}\right) .24,200-25,680\left(\mathrm{v}_{3}\right)$ and 27,700 - 29,400 $\mathrm{cm}^{-1}\left(\mathrm{v}_{4}\right)$. (Table 2). Six coordinate complexes with $\mathrm{O}_{\mathrm{h}}$ symmetry show three spin-allowed bands [25]. Which the highest energy band assignable to the ${ }^{4} \mathrm{~A}_{1 \mathrm{~g}} \rightarrow$ ${ }^{4} \mathrm{~A}_{2 \mathrm{~g}}$ transition, occurs above $30,000 \mathrm{~cm}^{-1}$. The spectra of the complaxes under study show four bands below $30000 \mathrm{~cm}^{-1}$ which cannot be interpreted in terms of idealized $\mathrm{O}_{\mathrm{h}}$ symmetry. The spectra can however be explained by assuming the presence of lower symmetry elements in the complexes, Such six-coordinated chromium can have either effective $c_{4 v}$ or $D_{4 h}$ symmetry. In the present complexes the four transitions observed can be assigned ${ }^{4} \mathrm{~B}_{1 \mathrm{~g}} \rightarrow{ }^{4} \mathrm{E}_{\mathrm{g}}^{\mathrm{a}}\left(\mathrm{v}_{1}\right),{ }^{4} \mathrm{~B}_{1 \mathrm{~g}} \rightarrow{ }^{4} \mathrm{~B}_{2 \mathrm{~g}}\left(\mathrm{v}_{2}\right),{ }^{4} \mathrm{~B}_{1 \mathrm{~g}} \rightarrow{ }^{4} \mathrm{E}_{\mathrm{g}}^{\mathrm{b}}\left(\mathrm{v}_{3}\right)$ and ${ }^{4} \mathrm{~B}_{1 \mathrm{~g}} \rightarrow{ }^{4} \mathrm{~A}_{1 \mathrm{~g}}^{\mathrm{a}}\left(\mathrm{v}_{4}\right)$ transitions arising from the lifting of the degeneracy of the orbital triplet (in octahedral symmetry) in the order of increasing energy and assuming the effective symmetry around the metal ion of $\mathrm{D}_{4 \mathrm{~h}}$. In $\mathrm{O}_{\mathrm{h}}$ symmetry $\left(\mathrm{v}_{1}\right)$ and $\left(\mathrm{v}_{2}\right)$ are derived from the 
${ }^{4} \mathrm{~T}_{2 \mathrm{~g}}$ level, whilst $\mathrm{v}_{3}$ and $\mathrm{v}_{4}$ from ${ }^{4} \mathrm{~T}_{1 \mathrm{~g}}(\mathrm{~F})$, The $\mathrm{C}_{4 \mathrm{v}}$ symmetry has been ruled out because of the greater splitting of the first band.

\subsection{Magnetic Moment of the Complexes}

The magnetic moment of these complexes, at room temperature (296 k), lie in the range of 3.71 - 3.84 B.M. as shown in (Table 2), which are close to spin only value of 3.86 B.M thereby, suggesting an octahedral geometry around the chromium ion.

\subsection{EPR Spectra of the Complexes}

The EPR spectra of the polycrystalline samples have been recorded (Figures 2(a)-(c)) at room temperature. The "g" values lie in the range 1.98 - 2.01 (Table 3). The "g" values are calculated using the expression.

$$
\mathrm{g}=2.0023(1-4 \lambda / 10 \mathrm{Dq})
$$

where $\lambda$ is the spin-orbit coupling constant for the metal ion in the complex. Owen [26] noted that the reduction of spin orbit coupling from the free-ion value of $90 \mathrm{~cm}^{-1}$ for chromium (III) can be employed as a measure of metal-ligand covalency. It is possible to define a covalency parameter analogous to the nephclauxetic parameter which is the ratio of the spin-orbit coupling constant for the complex and the free $\mathrm{Cr}^{3+}$ ions.

Energy of the first spin allowed transition ${ }^{4} \mathrm{~A}_{2 \mathrm{~g}} \rightarrow{ }^{4} \mathrm{~T}_{2 \mathrm{~g}}$ directly gives the value of $10 \mathrm{Dq}$.

Spin Hamiltonian for $\mathrm{Cr}(\mathrm{III})$ complexes ( $\mathrm{S}=3 / 2)$ may be written as

Table 2. Magnetic and electronic spectral bands of chromium(III) complexes.

\begin{tabular}{|c|c|c|c|c|c|}
\hline Complex & (B.M) & $\mathrm{V}_{1}\left(\mathrm{~cm}^{-1}\right)$ & $\mathrm{V}_{2}\left(\mathrm{~cm}^{-1}\right)$ & $\mathrm{V}_{3}\left(\mathrm{~cm}^{-1}\right)$ & $\mathrm{V}_{4}\left(\mathrm{~cm}^{-1}\right)$ \\
\hline$\left[\mathrm{Cr}(\mathrm{BDP}) \mathrm{CI}_{2}\right] \mathrm{CI}$ & 3.82 & 18,660 & 22,465 & 24,940 & 27,890 \\
\hline$\left[\mathrm{Cr}(\mathrm{BDP})\left(\mathrm{NO}_{3}\right)_{2}\right]\left(\mathrm{NO}_{3}\right)$ & 3.84 & 18,436 & 22,685 & 25,068 & 27,970 \\
\hline$\left[\mathrm{Cr}(\mathrm{BDP})(\mathrm{NCS})_{2}\right](\mathrm{NCS})$ & 3.84 & 18,365 & 22,470 & 25,686 & 28,096 \\
\hline$\left[\mathrm{Cr}(\mathrm{ADP}) \mathrm{CI}_{3}\right] \mathrm{CI}$ & 3.82 & 17,980 & 22,654 & 24,212 & 28,220 \\
\hline$\left[\mathrm{Cr}(\mathrm{ADP})\left(\mathrm{NO}_{3}\right)_{2}\right]\left(\mathrm{NO}_{3}\right)$ & 3.76 & 18,024 & 22,568 & 24,510 & 29,411 \\
\hline$\left[\mathrm{Cr}(\mathrm{ADP})(\mathrm{NCS})_{2}\right](\mathrm{NCS})$ & 3.78 & 18,181 & 22,764 & 24,468 & 28,901 \\
\hline$\left[\mathrm{CR}(\mathrm{DDP}) \mathrm{CI}_{2}\right] \mathrm{CI}$ & 3.71 & 18,840 & 22,106 & 25,568 & 28,104 \\
\hline$\left[\mathrm{Cr}(\mathrm{DDP})\left(\mathrm{NO}_{3}\right)_{2}\right]\left(\mathrm{NO}_{3}\right)$ & 3.76 & 17,993 & 22,440 & 24,960 & 28,397 \\
\hline$\left[\mathrm{Cr}(\mathrm{DDP})(\mathrm{NCS})_{2}\right](\mathrm{NCS})$ & 3.75 & 17,465 & 22,297 & 24,400 & 27,777 \\
\hline
\end{tabular}

Table 3. Ligand field parameters and ESR spectral data of chromium(III) complexes.

\begin{tabular}{|c|c|c|c|c|c|c|c|}
\hline Complex & Dq (em-1) & B (em-1) & $\mathrm{C}$ & $\beta$ & $\mathrm{Z}$ & LFSE Kj/Mole & g \\
\hline$\left[\mathrm{Cr}(\mathrm{BDP}) \mathrm{Cl}_{2}\right] \mathrm{CI}$ & 2246.50 & 338.70 & 1354.80 & 0.37 & 0.48 & 268.00 & 0.98 \\
\hline$\left[\mathrm{Cr}(\mathrm{BDp})\left(\mathrm{NO}_{3}\right)_{2}\right]\left(\mathrm{NO}_{3}\right)$ & 2268.50 & 382.70 & 1531.60 & 0.41 & 0.23 & 271.00 & 2.00 \\
\hline$\left[\mathrm{Cr}(\mathrm{BDP})(\mathrm{NCS})_{2}\right](\mathrm{NCS})$ & 2247.00 & 368.60 & 1474.40 & 0.40 & 0.29 & 268.00 & 1.99 \\
\hline$\left[\mathrm{Cr}(\mathrm{ADP}) \mathrm{CI}_{2}\right] \mathrm{Cl}$ & 2265.40 & 427.00 & 1708.00 & 0.46 & 0.07 & 270.60 & 1.99 \\
\hline$\left[\mathrm{Cr}(\mathrm{ADP})\left(\mathrm{NO}_{3}\right)_{2}\right]\left(\mathrm{NO}_{3}\right)$ & 2256.80 & 413.50 & 1654.00 & 0.45 & 0.11 & 269.60 & 2.00 \\
\hline$\left[\mathrm{Cr}(\mathrm{ADP})(\mathrm{NCS})_{2}\right](\mathrm{NCS})$ & 2276.40 & 417.00 & 1668.00 & 0.45 & 0.10 & 271.90 & 1.98 \\
\hline$\left[\mathrm{Cr}(\mathrm{DDP}) \mathrm{CI}_{2}\right] \mathrm{Cl}$ & 2210.60 & 287.00 & 1148.00 & 0.31 & 0.11 & 264.00 & 1.99 \\
\hline$\left[\mathrm{Cr}(\mathrm{DDP})\left(\mathrm{NO}_{3}\right)_{2}\right]\left(\mathrm{NO}_{3}\right)$ & 2244.00 & 403.71 & 1641.80 & 0.44 & 0.14 & 268.00 & 1.97 \\
\hline$\left[\mathrm{Cr}(\mathrm{DDP})(\mathrm{NCS})_{2}\right](\mathrm{NCS})$ & 2229.70 & 445.20 & 1780.10 & 0.48 & 0.02 & 266.00 & 1.98 \\
\hline
\end{tabular}


Scan range- 2000

Field Set-3200
Time Constant-

Scan Time-Hrs
Modulation Amplitude-1

Modulation Frequency-
Receive Gain- $4 \times 10$

Temperature-RT
Microwave power-5

Microwave Frequency- 9.1

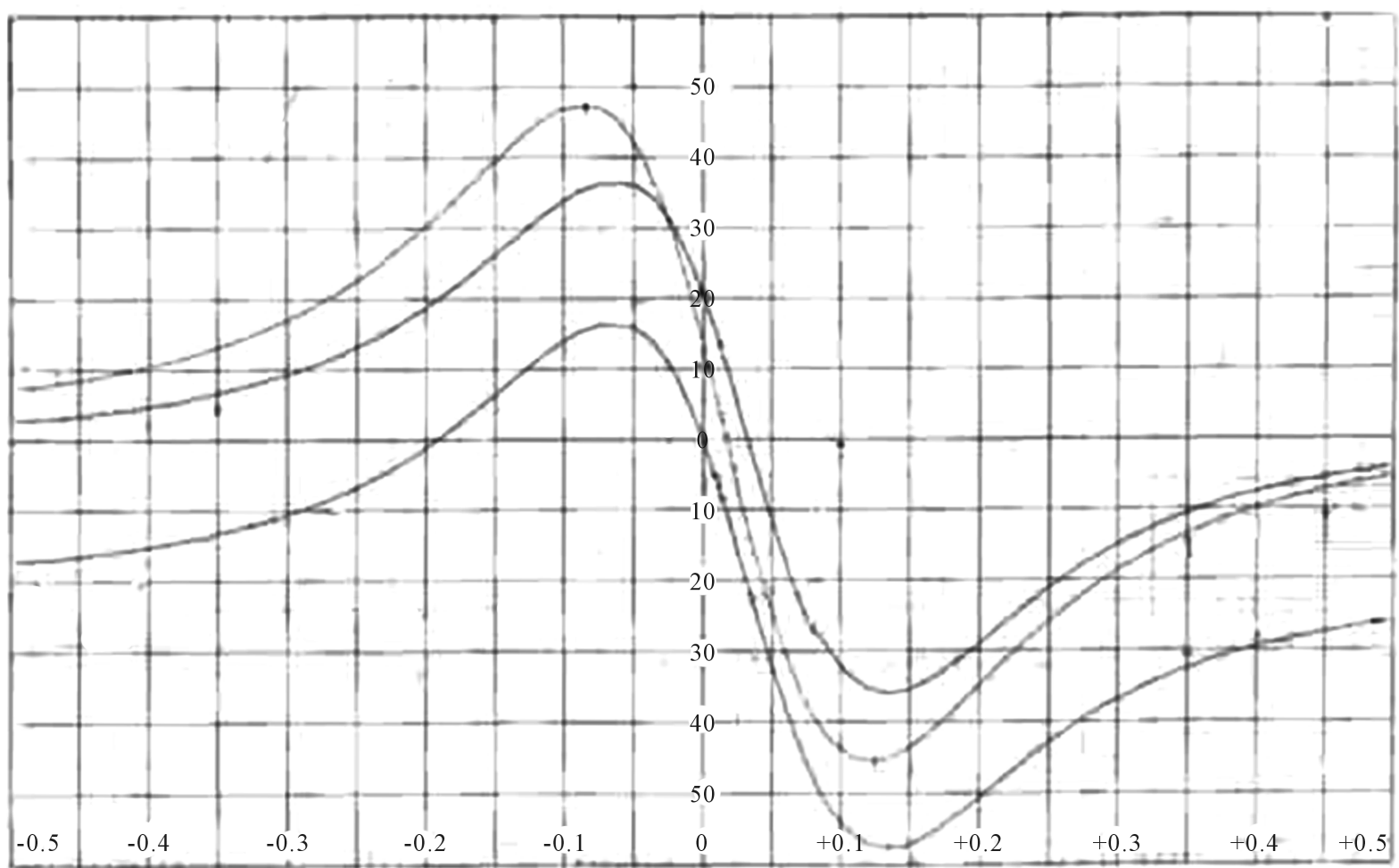

(a)

Scan range- 2000 Field Set-3200
Time ConstantScan Time-Hrs
Modulation Amplitude-1 Modulation Frequency-
Receive Gain- $5 \times 10 \times 10$

Temperature-RT
Microwave power-5

Microwave Frequency- 9.1

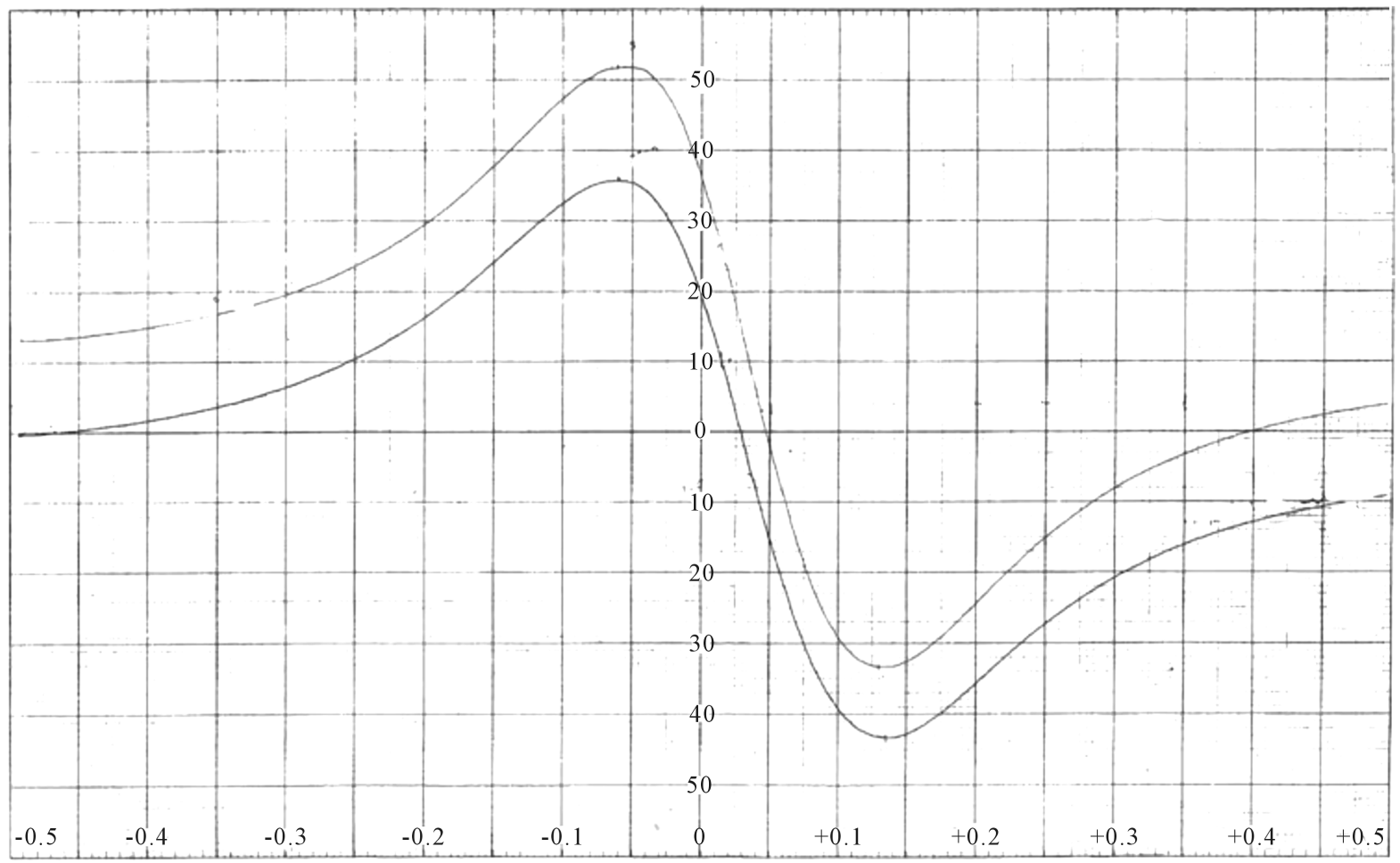

(b) 


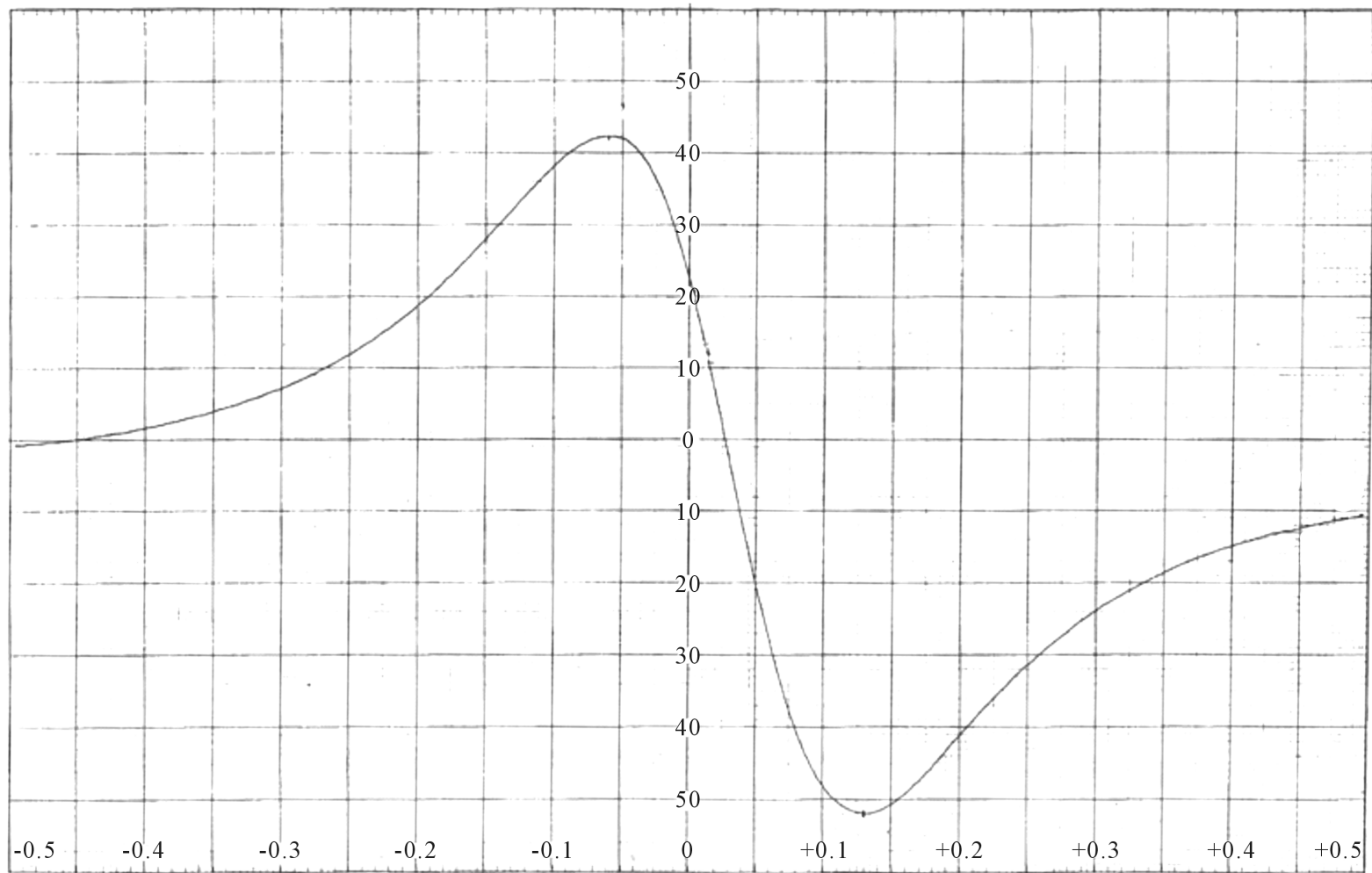

(c)

Figure 2. (a) ESR spectrum of $\left[\mathrm{Cr}(\mathrm{ADP})\left(\mathrm{NO}_{3}\right)_{2}\right]\left(\mathrm{NO}_{3}\right)$ complex; (b) ESR spectrum of $\left[\mathrm{Cr}(\mathrm{DDP}) \mathrm{Cl}{ }_{2}\right] \mathrm{Cl}$ complex; (c) ESR spectrum of $\left[\mathrm{Cr}(\mathrm{DDP})(\mathrm{SCN})_{2}\right](\mathrm{SCN})$ complex.

$$
\mathrm{H}=\mathrm{g} \beta \text {.S.H. }+\mathrm{D}\left[\mathrm{S}_{\mathrm{z}}^{2}-5 / 4\right]+\mathrm{E}\left[\mathrm{S}_{\mathrm{z}}^{2}-\mathrm{S}_{\mathrm{y}}^{2}\right]
$$

The ${ }^{4} \mathrm{~F}$ state of $\mathrm{d}^{3}$ ion in octahedral symmetry has the orbital singlet state lowest in energy with all excited states at much higher energies. Thus, the $\mathrm{d}^{3}$ ion has relatively long spin relaxation effects and gives narrow ESR absorption line, even at room temperature. In octahedral symmetry, ground state belongs to $A_{2 \mathrm{~g}}$ irreducible representation and is connected through the spin-orbit coupling to the excited $\mathrm{T}_{2 \mathrm{~g}}$ state only, and so, the $\mathrm{g}$ and $\mathrm{A}$ terms are very nearly isotropic even in highly distorted crystal fields. In $\mathrm{d}^{3}$ ions the symmetry of the nearly field is primarily exhibited through spin-spin terms $\mathrm{D}$ and $\mathrm{E}$.

Thus, on the basis of elemental analysis, molar conductance measurements, magnetic susceptibility measurements, ir, electronic. and esr spectral studies, the following structures may be proposed for the complexes. (Structure of complexes) (Figures 3(a)-(c)).

\section{Ligand Field Parameters}

Various ligand field parameters have been evaluated and are listed in Table 3 and Table 4. The energy of the first spin-allowed transition ${ }^{4} \mathrm{~B}_{1 \mathrm{~g}} \rightarrow{ }^{4} \mathrm{E}_{\mathrm{g}}^{\mathrm{a}}$ directly gives the values of $10 \mathrm{Dq}$. B has been evaluated from the relation,

$$
\mathrm{B}=\frac{2 \mathrm{v}_{1}^{2}-3 \mathrm{v}_{1} \mathrm{v}_{2}+\mathrm{v}_{2}^{2}}{15 \mathrm{v}_{2}-27 \mathrm{v}_{1}}
$$

where $v_{1}$ and $v_{2}$ are the energies of the transitions $4 \mathrm{~B}_{1 \mathrm{~g}} \rightarrow 4 \mathrm{E}_{\mathrm{g}}^{\mathrm{a}}$ and, $4 \mathrm{~B}_{1 \mathrm{~g}} \rightarrow 4 \mathrm{~B}_{2 \mathrm{~g}}$, respectively, the nephelauxetic paramter, $\beta$ is readily obtained using the relation $\beta=\mathrm{B}$ (complex)/B (free ion), where $\mathrm{B}$ (free ion) $=918$ $\mathrm{cm}^{-1}$. The results are presented in Table 3. The value of $\beta$ lies in the range of $0.31-0.52$. These values indicate that the complexes have appreciable covalent character. 
Table 4. NSH hamiltonian parameters of the chromium(III) complexes.

\begin{tabular}{ccccccc}
\hline Complex & Dt & Ds & DS & DT & DQ & DT/DQ \\
\hline$\left[\mathrm{Cr}(\mathrm{BDP}) \mathrm{Cl}_{2}\right] \mathrm{Cl}$ & 2132.60 & 1094.00 & 7658.30 & 28908.30 & 865552.80 & 0.033 \\
{$\left[\mathrm{Cr}(\mathrm{BDP})\left(\mathrm{NO}_{3}\right)_{2}\right](\mathrm{NO})_{3}$} & 2106.90 & 1150.00 & 8050.00 & 28559.90 & 853771.90 & 0.033 \\
{$\left[\mathrm{Cr}(\mathrm{BDP})(\mathrm{NCS})_{2}\right](\mathrm{NCS})$} & 2098.80 & 1151.80 & 8062.80 & 28450.20 & 850844.10 & 0.033 \\
{$\left[\mathrm{Cr}(\mathrm{ADP}) \mathrm{Cl}_{2}\right] \mathrm{Cl}$} & 2054.80 & 1193.70 & 8356.25 & 27853.70 & 831203.60 & 0.034 \\
{$\left[\mathrm{Cr}(\mathrm{ADP})\left(\mathrm{NO}_{3}\right)_{2}\right]\left(\mathrm{NO}_{3}\right)$} & 2059.90 & 1277.50 & 8942.60 & 27922.80 & 833656.70 & 0.033 \\
{$\left[\mathrm{Cr}(\mathrm{ADP})\left(\mathrm{NCS}_{2}\right](\mathrm{NCS})\right.$} & 2077.80 & 1353.70 & 10254.70 & 28165.50 & 840903.10 & 0.033 \\
{$[\mathrm{Cr}(\mathrm{DDP}) \mathrm{Cl}$} & \\
2 & 2153.10 & 1095.40 & 7668.10 & 29186.20 & 875454.30 & 0.033 \\
$\left.\left[\mathrm{Cr}(\mathrm{DDP})\left(\mathrm{NO}_{3}\right)_{2}\right](\mathrm{NO})_{3}\right)$ & 2056.30 & 1305.60 & 9139.20 & 27874.00 & 832443.20 & 0.033 \\
{$\left[\mathrm{Cr}(\mathrm{DDP})\left(\mathrm{NCS}_{2}\right](\mathrm{NCS})\right.$} & 1996.00 & 1302.80 & 9119.80 & 27056.70 & 806619.00 & 0.034 \\
\hline
\end{tabular}

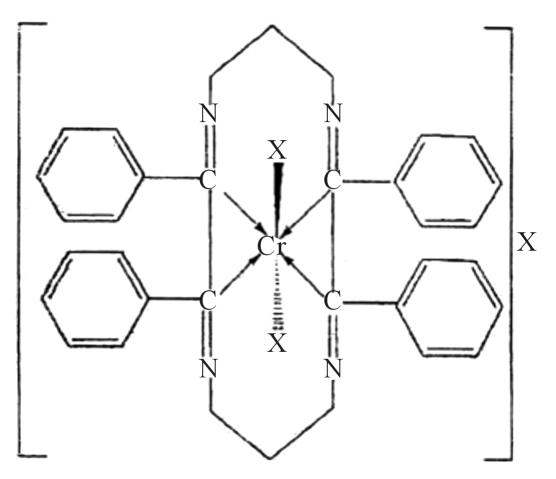

$\left[\mathrm{Cr}(\mathrm{BDP}) \mathrm{X}_{2}\right] \mathrm{X}$

(a)

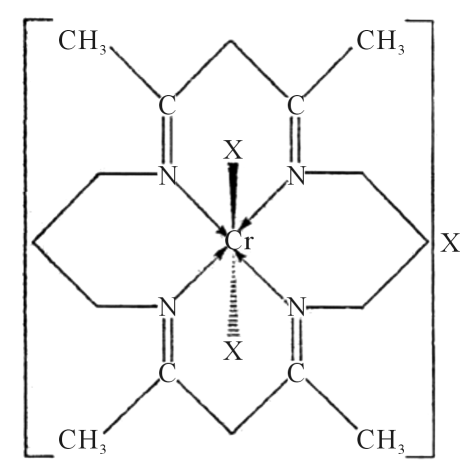

$\left[\mathrm{Cr}(\mathrm{ADP}) \mathrm{X}_{2}\right] \mathrm{X}$

(b)

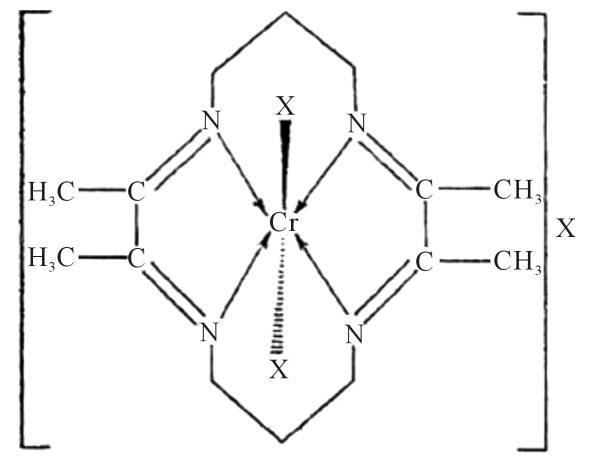

$\left[\mathrm{Cr}(\mathrm{DDP}) \mathrm{X}_{2}\right] \mathrm{X}$

(c)

Figure 3. Structure of complexes.

According to jorgensen [27] for the $3 d$ transition. B is well expressed by the relation $B\left(\mathrm{~cm}^{-1}\right)=384+58 q+$ $124(Z+1)-540 /(Z+1)$

From this relation the values of $Z$ for the present complexes lie in the range 0.02 - 0.48 (Table 3 ) which is considerably below the format +3 oxidation state of chromium. Some other ligand field parameters have also been calculated (Table 3 ).

The transition $v_{2}$ is equal to $10 \mathrm{Dq}^{\mathrm{xy}}$ and the saparation between $\mathrm{v}_{1}$ and $\mathrm{v}_{2}$ is of first order (35/4) $\mathrm{D}_{t}$ and $\mathrm{D}_{t}$ is related to the in-plane and out-of-plane field strengths as $D_{t}=(4 / 7)\left[\mathrm{Dq}^{\mathrm{xy}}\right.$ and $\mathrm{Dq}^{\mathrm{z}}$ are in-plane (xy) and out-ofplane $(\mathrm{z})$ Field strength, respectively. The radial parameter $\mathrm{D}_{\mathrm{s}}$ has been ealculated from the splitting of 


$$
{ }^{4} \mathrm{~B}_{2 \mathrm{~g}}{ }_{{ }^{4} \mathrm{E}_{1 \mathrm{~g}}^{\mathrm{a}}\left(\mathrm{v}_{1}\right)+2 \mathrm{D}_{\mathrm{s}}+3 \backslash 4 \mathrm{D}_{\mathrm{t}},}^{{ }^{4} \mathrm{~A}_{1 \mathrm{~g}}^{\mathrm{a}}\left(\mathrm{v}_{4}\right)-4 \mathrm{D}_{\mathrm{s}}+2 \mathrm{D}_{1} \text { separation } 6 \mathrm{D}_{\mathrm{s}}+5 / 4 \mathrm{~d}_{\mathrm{t}}}
$$

The values of these parameters (Table 4) are comparable to those observed for chromium complexes involving similar set of chromophore [28]. However, it may be pointed out that these parameters are not standardised and thus require modifications. To overcome the shortcoming of various parameters of the classical Hamiltonian for tetragonal complexes, Lever et al. [29] [30] had advanced the theory of a Normalised Spherical Harmonic (NSH) Hamiltonian. The NSH parameters DQ, DS, DT, $\mathrm{DQ}^{\mathrm{xy}}$, and $\mathrm{DQ}^{\mathrm{z}}$ are fully capitalized to relate them to the corresponding crystal field parameters. Yet emphasize their distinction. The NSH classical parameters are related by,

$$
\begin{aligned}
& \mathrm{DS}=-7 \mathrm{Ds} \\
& \mathrm{DT}+[(7 \sqrt{15}) / 2] \mathrm{D}_{1} \\
& \mathrm{DQ}=\left(6 \sqrt{21} \mathrm{DDq}^{\mathrm{xy}}-[7 \sqrt{21}] \mathrm{DT}\right.
\end{aligned}
$$

There are several advantages of NSH Hamiltonian theory: 1) the theory takes into account an off-diagonal contribution to $\mathrm{D}_{1} 2$ 2) DQ is a measure of the average ligand field experienced by the metal ion, unlike the classical Dq which is the measure of the in-plane field only and 3) the parameters of NSH theory are independent of the coordinate system used for the calculated and may be compared with the crystal field or angular overlap parameters $\mathrm{DQ}^{\mathrm{xy}}$ (in plane field strength) and $\mathrm{DQ}^{\mathrm{z}}$ (out-of-plane field strength) which are determined by the equations.

$$
\begin{aligned}
& \mathrm{DQ}=(1 / 6)\left[\left(4 \mathrm{DQ}^{\mathrm{xy}}=2 \mathrm{DQ}^{\mathrm{z}}\right)\right. \\
& \mathrm{DT}=(\sqrt{5} \sqrt{7})\left[\mathrm{DQ}^{\mathrm{xy}}-\mathrm{DQ}\right]
\end{aligned}
$$

However it may be pointed out that these parameters have artificial significance. For DQ itself is a measure of average ligand field strength. Further, the ratio (DT/DQ) has been shown to be a good measure of the degree of tetragonal distortion. The values of (DT/DQ) lie in the range $0.033-0.034$. These values are much lower then the limiting value (0.4226) for a square planar complex and suggest a small distortion from idealized cubic symmetry in these complexes.

\section{Biological Study}

The ligand (L) 2,3,9,10 tetraphenyl-1,4,8,11-tetraazacyclo tetradeca-1,3,8,10 tetraene. (BPD), ligand free metal ions and its complexes were evaluated against different species of bacteria and fungi as per the procedure reported earlier [31]-[34]. In both, antibacterial and antifungal studies ligand free metal ions in solution show inhibition capacity slighty more than the ligand but much less than complexes against all the species under study.

\subsection{Antibacterial Screening}

The compounds were screened against Sarcinalutea (gram-positive) and Escherchiacoli (gram-negative) bacteria, as growth inhibitor by disc diffusion technique [31] [32]. The results of the antibacterial screening show the maximum inhibition by the $\left(\mathrm{CrL}\left(\mathrm{NO}_{3}\right)\right] \mathrm{NO}_{3}$ complexes.

\subsection{Antifungal Screening}

Aspergillus-niger and Aspergillus-glaucus fungi were used as the test organism for all the newly synthesized compounds for the purpose of antifungal screening by agar plate technique [33] [34]. All the complexes show nearly the same inhibition.

\section{Conclusion}

The present study revealed six-coordinated octahedral geometry for the $\mathrm{Cr}(\mathrm{III})$ complexes. All the ligands act as 
a tetradentate manner coordinating through four nitrogons of the azonethine groups in an $\mathrm{N}, \mathrm{N}, \mathrm{N}, \mathrm{N}$ fashion moreover, the fungicidal data reveal that the complexes were superior to the free ligand in the inhibition of the tested fungi. It is proposed that concentration plays a vital role in increasing the degree of inhibition, the activity increased with increasing concentration of the complexes.

\section{Acknowledgements}

We are thankful to DRDO New Delhi for financial and I.I.T. Bombay for Recording EPR spectra.

\section{References}

[1] Wang, Y., Liu, Y., Luo, J., Qi, H., Li, X., Nin, M., Liu, M., Shi, D., Zhu, W. and Cao, Y. (2011) Mettallomesogens Based on Platinum(II) Complexes: Synthesis, Luminescence and Polarized Emission. Dalton Transactions, 40, 50465051. http://dx.doi.org/10.1039/c0dt01515f

[2] Emeleus, L.C., Cupertino, D.C., Harris, S.G., Owens, S., Parsons, S., Swart, R.W., Tasker, P.A. and White, D.J. (2001) Diazopyrazolones as Weak Solvent Extract Ants for Copper from Ammonia Leach Solutions. Dalton Transactions, 2001, 1239-1245. http://dx.doi.org/10.1039/b101780m

[3] Oforka, N.C. and Mkpenie, V.N. (2007) A New Method of Synthesis of Azo Schiff Base Ligands with Azo and Azomethine Synthesis of N-4-Methoxy-Benzylidene-2-(3-Hydroxyphenylazo)-5-Hydroxy-Aniline and Its Nickel(II) Complexes. Chinese Journal of Chemistry, 25, 869-871. http://dx.doi.org/10.1002/cjoc.200790159

[4] Hudson, S.A. and Maitlis, P.M. (1993) Calamitic Metallomesogens: Metal-Containing Liquid Crystals with Rodelike Shapes. Chemical Reviews, 93, 861-885. http://dx.doi.org/10.1021/cr00019a002

[5] Halve, A. and Goyal, A. (2001) Synthesis and Crystal Structure of 2-(2,3,4-Trimethoxy-6-Methylbenzylideneamino)phenol. Oriental Journal of Chemistry, 12, 87-88.

[6] Pandeya, S.N., Sriram, D., Nath, G. and de Clercq, E. (1999) Synthesis and Pharmacological Evaluations of Some Novel Isatin Derivatives for Antimicrobial Activity. II Farmaco, 54, 624-628. http://dx.doi.org/10.1016/S0014-827X(99)00075-0

[7] Lashanizadegan, M. and Jamshidbeigi, M. (2012) Synthesis of N,N’-Bis[4-(benzeneazo)salicylaldehyde]4-methyl-1-2phenylenediamine and Its Transition Metal Complexes. Synthesis and Reactivity in Inorganic, Metal-Organic, and Nano-Metal Chemistry, 42, 507-512. http://dx.doi.org/10.1080/15533174.2011.613432

[8] Hodnett, E.M. and Dunn, W.J. (1970) Synthesis of Novel Azo Schiff Base Bis[5,(4-methoxyphenylazo)-2-hydroxy-3methoxy benzaldehyde]-1,2-Phenylenediamine. Journal of Medicinal Chemistry, 13, 768-770. http://dx.doi.org/10.1021/jm00298a054

[9] Desai, S.B., Desai, P.B. and Desai, K.R. (2001) Synthesis and Spectroscopic Studies of New Schiff Bases. Heterocyclic Communications, 7, 83-90.

[10] Mitu, L., Ilis, M., Raman, N., Imran, M. and Ravichandran, S. (2012) Transition Metal Complexes of IsonicotinoylHydrazone-4-Diphenylaminobenzaldehyde: Synthesis, Characterization and Antimicrobial Studies. E-Journal of Chemistry, 9, 365-372. http://dx.doi.org/10.1155/2012/298175

[11] Samadhiya, S. and Halve, A. (2001) 1-(4-\{[(E)-(4-Diethylamino-2-Hydroxyphenyl)Methylene]Amino $\}$ phenyl)ethanone. Oriental Journal of Chemistry, 17, 119-122.

[12] Chandra, S. and Kumar, A. (2013) Spectral, Thermal and Morphological Studies on Chromium Nanoparticles. Spectrochim Acta A: Molecular and Biomolecular Spectroscopy, 102, 250-255.

[13] Chandra, S., Bargujar, S. Nirwal, R. and Yadav, N. (2013) Synthesis, Spectral, Characterization and Biological Evaluation of Copper(II) and Nickel(II) Complexes with Thiosemicorbazone Derived from a Bidentate Schiff Base. Spectrochim Acta A: Molecular and Biomolecular Spectroscopy, 106, 91-98.

[14] Chandra, S. and Ruchi (2013) Synthesis, Spectroscopic Characterization, Molecular Modeling and Antimicrobial Activities of Mn(II), Co(II), Ni(II) Cu(II) Complexes Containing the Tetra Dentate Aza Schiff Base Ligand. Spectrochim Acta A: Molecular and Biomolecular Spectroscopy, 103, 338-348. http://dx.doi.org/10.1016/j.saa.2012.10.065

[15] Verma, S., Chandra, S., Dev, U. and Joshi, N. (2009) Synthesis, Spectral and Biological Studies of Nitrogen-Sulphur Donor Macrocyclic Ligand and Their Transition Metal Complexes. Spectrochimica Acta, 74, 370-374.

[16] Khan, T.A., Tabassum, S., Azim, Y. and Shakir, M. (2004) Synthesis and Physico-Chemical Studies on 18-Membered Octaazamacrocylic Complexes of $\mathrm{Mn}(\mathrm{II}), \mathrm{Co}(\mathrm{II}), \mathrm{Ni}(\mathrm{II}), \mathrm{Cu}(\mathrm{II})$ and $\mathrm{Zn}(\mathrm{II})$ Ions. Synthesis and Reactivity in Inorganic and Metal-Organic Chemistry, 34, 1305-1318. http://dx.doi.org/10.1081/SIM-200026200

[17] Gupta, S.K. and Kushwah, Y.S. (2001) Mononuclear Iron(III) Macrocyclic Complexes Derived from 4-Methyl-2,6-di(Formyl/benzoyl)phenal and Diamines: Synthesis, Spectral Speciation and Electrochemical Behaviour. Polyhedron, 20, 
2019-2025. http://dx.doi.org/10.1016/S0277-5387(01)00786-0

[18] Qian, M., Gou, S.H., Ju, H.X., Huang, W., Duan, C.Y. and You, X.Z. (2000) A Mononuclear Manganese(II) Complex of an Asymmetric Macrocyclic Ligand with a Sing Contraction [MnHLZ(ClO $\left.\left.\mathrm{Cl}_{4}\right)\right] \cdot 2.5 \mathrm{H}_{2} \mathrm{O}$. Transition Metal Chemistry, 25, 584-588. http://dx.doi.org/10.1023/A:1007050902958

[19] Chandra, S. and Gupta, L.K. (2002) Chromium(III), Manganese(II), Iron(III), Cobalt(II), Nickel (II), and Copper(II) Complexes with a Pentadentate, 15-Membered New Macrocyclic Ligand. Transition Metal Chemistry, 27, 196-199. http://dx.doi.org/10.1023/A:1013935602736

[20] Schwarz, K. and Mertz, W. (1957) Efficancy of Chromium Supplementation in Athletes: Emphasis on Anabolism. Archives of Biochemistry and Biophysics, 72, 515. http://dx.doi.org/10.1016/0003-9861(57)90228-X

[21] Schwarz, K. and Mertz, W. (1959) Chromium in Plants Comparison between the Concentration of Chromium in Brazilian Nonhypo and Hypoglcemic Plants. M.J. Physial, 196, 614.

[22] Jennette, K.W. (1982) Hand Book on Metalloproteins. Journal of the American Chemical Society, $108,874$. http://dx.doi.org/10.1021/ja00367a050

[23] Burrows, D. (1983) Chromium Metabolism and Twicity. CRC Press, Boca Raton.

[24] Vincent, J.B. (2001) The Bioinorganic Chemistry of Chromium (III). Polyhedron, 20, 1-26.

[25] Perumareddi, J.R. (1969) Electronic Spectra of Quardarate Cr(III) Complexes. Coordination Chemistry Review, 573.

[26] Jorgensen, C.K. (1967) Neptunium(VII), Nobelium (II), 126(IV) and Other Unexpected Oxidation States of TransUranium Elements. Helvetica Chimica Acta, 131.

[27] Lever, A.B.P. (1968) Ligand Field Parameter. Coordination Chemistry Review, 4, 119. http://dx.doi.org/10.1016/S0010-8545(00)80107-1

[28] Kumar, U.A. and Chandra, S. (1993) Semicarbazone, Thiosemicarbozone Cr(III) Complexes. Transition Metal Chemistry, 18, 342-344.

[29] Chandra, S. and Sharma, S. (2007) Synthesis and Spectral Studies of Transition Metal Complexes with 1,5:11,15-Dimethane-2,4,10,12,-Tetramethyl-[1,5,9,13]-Tetraazahexadeca-1,3,5,6,10,11,13,15,16,20-Decene a Sixteen-Membered Tetradentate Macrocyclic Ligand. Transition Metal Chemistry, 32, 150-154. http://dx.doi.org/10.1007/s11243-006-0117-y

[30] Owen, J. and Roy, P. (1955) The Colour and Magnetic Properties of Hydrated Iorn Group Salts and Evidence for Covalent Bonding. Proceedings of the Royal Society A London, 227, 183-200. http://dx.doi.org/10.1098/rspa.1955.0003

[31] Chandra, S., Jain, D. and Sharma, A.K. (2009) Coordination Modes of a Schiff Base Pentadentate Derivative of 4-Aminoantipyrine with Cobalt(II), Nickel(II) and Copper(II) Metal Ions: Synthesis, Spectroscopic and Antimicrobial Studies. Molecules, 14, 174-190.

[32] Singh, D.P., Kamboj, M., Kumar, K., Jain, K. and Sharma, C. (2011) Divalent Metal Macrocyclic Complexes Derived from Acetonylacetone and Carbohydrazide with Their Spectroscopic and Antibacterial Studies. Journal of Coordination Chemistry, 64, 502-510.

[33] Grurumoorthy, P., Ravichandran, J., Karthikeyan, N., Palani, P. and Kalilur, R.A. (2012) Template Synthesis of Polyaza Macrocyclic Copper(II) and Nickel(II) Complexes. Spectral Characterization and Antimicrobial Studies. Bulletin of the Korean Chemical Society, 33, 2279.

[34] Chandra, S. and Pipil, P. (2013) EPR, IR, Mass and Electronic Spectroscopic Studies on Newly Synthesized 23,24-Dioxo1,6,9,12,17,20-Hexaazacyclotracosa-1,5,12,16-Tetraene Macrocyclic Ligand(L) and Its Transition Metal Complexes. Journal of Chemical and Pharmaceutical Research, 5, 99-104. 